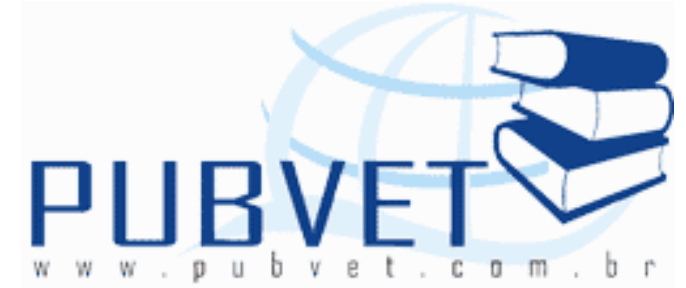

PUBVET, Publicações em Medicina Veterinária e Zootecnia.

\title{
Aplicação do náilon monofilamento na reparação intra-articular da ruptura do ligamento cruzado cranial em cães
}
Luiz Fernando Lucas Ferreira ${ }^{1}$, Antônio Último de Carvalho ${ }^{2}$ e Homem Israel Ferreira $^{3}$

\begin{abstract}
${ }^{1}$ Professor assistente de Clínica e Cirurgia e Obstetrícia de pequenos Animais da PUC MINAS BETIM - Ifvet@hotmail.com Aluno do Programa de PósGraduação em Cirurgia Veterinária da FCAV/UNESP/JABOTICABAL

${ }^{2}$ Professor do departamento de CCV da E.V. da UFMG

${ }^{3}$ Professor aposentado da E.V. da UFMG
\end{abstract}

\section{Resumo}

No presente trabalho, avaliou-se a eficiência do náilon monofilamento para substituição do ligamento cruzado cranial na reparação intra-articular da ruptura do mesmo. Utilizou-se 18 animais de raça não definida, de ambos os sexos, com peso de $16 \mathrm{~kg}$ a $35 \mathrm{~kg}$, que foram submetidos à artrotomia lateral da articulação fêmoro-tíbio-patelar para reparação experimental da ruptura do ligamento cruzado cranial. Após observações clínicas constatou-se que a prótese de náilon monofilamento é eficaz na recuperação da função do membro pélvico, sendo capaz de promover estabilidade da articulação fêmorotíbio-patelar de forma simples e com baixo custo.

Palavras-chave: cão, ligamento cruzado cranial, náilon, prótese 


\title{
Monofilament nylon application in the intra-articular reparing of the cranial cruciate rupture in dogs
}

\begin{abstract}
At this present research, an evaluation of the efficiency of the nylon as a substitute of the cranial cruciate ligament in the intra-articular repairing of its rupture has been investigated. 18 dogs of unespecific breed, male and female, weighing over $15 \mathrm{~kg}$ were studied. They have been submitted to lateral arthrotomy of the knee for experimental repairing of the cranial cruciate ligament rupture. After clinical observations, it has been proved that the nylon is efficient as a prosthesis, being able to reestablish the knee joint so that the function of the hindlimb could be improved in a simple and not expensive manner.
\end{abstract}

Keywords: dog, cranial cruciate ligament, nylon, prosthesis.

\section{INTRODUÇÃO}

O primeiro relato da ruptura do ligamento cruzado cranial (RLCC) foi efetuado por Carlin em 1926. O ligamento cruzado cranial (LCC) previne a hiperextensão da articulação fêmoro-tíbio-patelar (FTP) a translação excessiva e limita a rotação interna da tíbia em relação ao fêmur. O LCC é a principal estrutura responsável pela estabilidade da articulação FTP (Knecht, 1976; Arnoczky \& Marshall, 1977; Brinker et al, 1990; Arnoczky, 1993). A RLCC é a principal alteração que acomete a articulação FTP de cães. É causa comum de claudicação do membro pélvico nesta espécie, devido à instabilidade articular e a osteoartrite (Hulse \& Shires, 1985). O tratamento da RLCC pode ser cirúrgico ou conservador, entretanto, este último não se mostra eficaz, tendo resultados positivos em longo prazo, apenas em cães com peso inferior a $15 \mathrm{~kg}$ (Vasseur, 1984). Em cães de grande porte o tratamento cirúrgico é indicado para recompor a estabilidade da articulação FTP (Vasseur et al, 1996). O tratamento 
FERREIRA, L.F.L., CARVALHO, A.U. e FERREIRA, H.I. Aplicação do náilon monofilamento na reparação intra-articular da ruptura do ligamento cruzado cranial em cães. PUBVET, Londrina, V. 7, N. 18, Ed. 241, Art. 1592, Setembro, 2013.

cirúrgico da RLCC pode ser efetuado por técnicas denominadas extraarticulares e intra-articulares (Johnson \& Johnson 1993; Moore \& Read, 1996). As técnicas intra-articulares têm como princípio a substituição do LCC rompido por outro material, a fim de restaurar a estabilidade articulação. O material utilizado pode ser enxerto autógeno (Arnoczky et al, 1979; Shires et al, 1984), alógeno (Vasseur et al, 1986) e sintético (Vasseur et al, 1996). A técnica intraarticular possibilita a reconstituição da anatomia original da articulação FTP, além de permitir a visualização e a inspeção dos componentes anatômicos desta articulação, possibilitando a avaliação de processos inflamatórios e degenerativos da cápsula e cartilagem articular, como o espessamento da cápsula, erosões da cartilagem e presença de osteófitos (Vasseur et al, 1996). Os materiais sintéticos tem se demonstrados vantajosos em relação a implantes autógenos e alógenos, pois eliminam a necessidade de banco de enxerto (enxertos alógenos) e, também, diminuem o trauma e o tempo cirúrgicos quando comparados aos enxertos autógenos. Ademais, materias sintéticos podem ter suas propriedades físico-mecânicas e químicas previamente testadas (Vasseur et al, 1996).

O objetivo deste trabalho foi avaliar a eficiência do fio de náilon monofilamento na reparação intra-articular da ruptura do ligamento cruzado em cães, através de análise clínica da recuperação funcional dos membros pélvicos operados.

\section{MATERIAL E MÉTODOS}

Foram utilizados, 18 cães de raça não definida, com peso variando de $16 \mathrm{~kg}$ a $35 \mathrm{~kg}$, provenientes do canil da Prefeitura Municipal de Belo Horizonte. Os animais foram submetidos a exame clínico geral de rotina, exames laboratoriais de sangue (hemograma completo) e urina rotina. Os animais foram, também, medicados com vermífugo e produtos ectoparasiticídas e submetidos à quarentena. Foram divididos aleatoriamente em três grupos de seis animais: grupo $A,(A 1-A 6)$; grupo $B(B 1-B 6)$ e grupo $C$ (C1-C6). Os 
FERREIRA, L.F.L., CARVALHO, A.U. e FERREIRA, H.I. Aplicação do náilon monofilamento na reparação intra-articular da ruptura do ligamento cruzado cranial em cães. PUBVET, Londrina, V. 7, N. 18, Ed. 241, Art. 1592, Setembro, 2013.

animais do grupo A foram os primeiros a serem operados e foram observados e avaliados pôr 90 dias. Os animais do grupo B foram observados e avaliados pôr 60 dias e os animais do grupo $C$ pôr 30 dias. Durante o período pósoperatório, cada grupo ficou em baia coletiva de $20 \mathrm{~m}^{2}$. Foram observados diariamente pôr um período de 20 minutos, quando eram soltos em uma área de grama de $200 \mathrm{~m} 2$. Para a avaliação da deambulação foi utilizada a classificação de graus de claudicação segundo Braden \& Brinker, 1973 (tab. 1).Semanalmente foi realizada avaliação da estabilidade da articulação operada (teste do movimento de gaveta e compressão da tíbia) utilizando a classificação proposta por Person, 1987 (tab. 2).

Os animais foram anestesiados e preparados conforme normas de rotina para anestesia geral e assepsia de campo operatório para cirurgias ortopédicas.

\section{TÉCNICA CIRÚRGICA}

A artrotomia lateral foi realizada e os ligamentos cruzados e meniscos identificados e inspecionados seguindo-se a seç̧ão do LCC em seus pontos de inserção. Com uma broca ${ }^{1}$ de 2,5 mm de diâmetro acoplada a uma furadeira elétrica de duas rotações ${ }^{2}$, perfura-se um túnel do ponto de inserção do LCC, superfície caudo-medial do côndilo lateral até a superfície do epicôndilo lateral. Uma segunda perfuração é realizada transversalmente do epicôndilo lateral até o medial. Uma terceira perfuração é realizada da superfície do epicôndilo medial até a face lateral do côndilo medial. Uma quarta perfuração é realizada da região crânio-medial do platô da tíbia (cranialmente ao ligamento intermeniscal) até a face lateral proximal da tíbia. Uma quinta perfuração é feita transversalmente da face lateral da tíbia até a sua face medial proximal. Uma sexta perfuração é realizada da face medial da tíbia até a superfície crânio-lateral do platô da tíbia. Durante as perfurações a broca é irrigada com

\footnotetext{
1 Broca 2,5mm longa, COFERMETA

2 Furadeira BLACK \& DECKER, 7.2 V 300/600 RPM, VP 840
} 
solução fisiológico estéril. Com o auxílio de uma agulha longa ${ }^{3},(10 \mathrm{~cm})$, calibre 12 , o fio de náilon monofilamento número $0.8^{4}$ é introduzido pôr todos os túneis, seguindo a formação de um "X" (fig. 1). Depois de confeccionado o "X" o fio é tracionado com o membro em extensão e fixado com o auxílio de um contra pino de náilon na face lateral da tíbia, extra capsular (fig. 2).

A articulação é lavada com solução fisiológica estéril e prossegui-se a artrorrafia, com fio de náilon monofilamento agulhado calibre 2-0 ${ }^{5}$. A cápsula articular foi suturada em um primeiro plano com ponto simples separado, sem que o fio atingisse a luz articular, e em um segundo plano com sutura de reverdin. O espaço morto foi reduzido com sutura contínua simples e a pele suturada com ponto simples separado.

A articulação operada foi imobilizada com aplicação de penso esparadrapado pôr 10 dias, quando foram retirados os pontos de pele. Após este período os animais ficaram com movimentação livre do membro operado.

Uma análise estatística descritiva de distribuição de frequência dos graus de claudicação foi realizada individualmente e por grupos através do sistema SAEG 7,0 VERSÃO 1997.

\section{RESULTADOS E DISCUSSÃO}

A técnica intra-articular para reparação da RLCC em cães que utiliza o fio de náilon como prótese foi considerada eficaz, resultados semelhantes foram obtidos por Johnson (1960). A utilização de materiais sintéticos para reparação da RLCC é uma opção importante a ser considerada na medicina veterinária (Butler, 1964; Gupta \& Brinker, 1969; Pearson, 1987; Selmi et al., 1996; Selmi et al., 1998).

\footnotetext{
3 Agulhas Hipodérmicas Delta LTDA. R. J.

4 Linhas Caiçara 0,8mm / 100m/31,5 kg

5 Ultralon 2-0 . p-214240, BIOSUT.
} 
FERREIRA, L.F.L., CARVALHO, A.U. e FERREIRA, H.I. Aplicação do náilon monofilamento na reparação intra-articular da ruptura do ligamento cruzado cranial em cães. PUBVET, Londrina, V. 7, N. 18, Ed. 241, Art. 1592, Setembro, 2013.

A não imobilização completa do membro operado no período de pós operatório não prejudicou a recuperação funcional do mesmo, fato este também observado por Butler (1964), Gupta e Brinker (1969).

A prótese de náilon proporcionou estabilização imediata da articulação fêmoro-tíbio-patelar, porém em alguns animais, (tab. 3) houve retorno da mobilidade cranial da tíbia em relação ao fêmur. Tal fato foi também relatado pôr Gupta \& Brinker (1969), Vasseur et al (1986), Person (1987).

Apesar de Johnson (1960) já ter descrito a utilização do náilon monofilametno para reparação da RLCC, o modo de aplicação e fixação do náilon como prótese no presente trabalho é diferente de qualquer outra técnica citada pela literatura, podendo assim, a mesma ser considerada inédita.

Todos os animais do grupo A retornaram à função normal do membro operado, atingindo grau IV na classificação de Braden \& Brinker (1973). O apoio do membro operado (grau II) iniciou entre o terceiro e décimo segundo dia do pós operatório e o retorno à função normal do membro (grau IV) entre o décimo sexto e trigésimo nono dia do pós operatório (figura. 3).

Todos os animais do grupo B retomaram a função normal do membro operado, atingindo grau IV na classificação de Braden \& Brinker (1973). O apoio do membro operado (grau II) iniciou entre o sexto e décimo primeiro dia do pós operatório e o retorno à função normal do membro (grau IV) entre o décimo quinto e quadragésimo terceiro dia do pós operatório (figura. 4).

Três animais do grupo $C,(C 1, C 4$ e $C 6)$ não retornaram à função normal do membro operado atingindo apenas grau III da classificação de Braden \& Brinker (1973). Os animais C2, C3 e C5 retornaram á função normal do membro (grau IV) entre os dias décimo sexto e vigésimo terceiro do pós operatório (figura. 5). À análise dos gráficos I, II, III, pode-se afirmar que este resultado do grupo $C$ é normal, uma vez que o período de observação de pós operatório foi de 30 dias. Pois os animais do grupo $A$ e grupo $B$ somente foram atingir grau IV, em 100\% dos animais de cada grupo, após 40 dias de pós operatório. 
Em todos os animais foi observada discreta atrofia da musculatura do membro operado, fato este observado pôr Vasseur et al (1996). Contradizendo tal resultado, Gupta \& Brinker (1969) ao trabalharem com a prótese de dacron na reparação da RLCC não observaram atrofia da musculatura do membro operado.

\section{CONCLUSÃO}

A prótese de náilon monofilamento é eficaz na reparação da RLCC, permitindo a recuperação funcional do membro pélvico. Sua facilidade de implantação, baixo custo e eficiência sinalizam para a continuidade dos estudos, para avanço da medicina veterinária.

\section{TABELAS}

Tabela 1 - Classificação dos graus de claudicação segundo Braden \& Brinker (1973).

\begin{tabular}{|c|}
\hline $\begin{array}{l}\text { Grau II - uso e apoio infreqüente do membro em estação e ao } \\
\text { caminhar. Não suportando peso na extremidade, elevando-o ao } \\
\text { correr. }\end{array}$ \\
\hline $\begin{array}{l}\text { Grau III - uso claudicante do membro. Suporte parcial do peso na } \\
\text { extremidade, elevando-o ao correr. }\end{array}$ \\
\hline
\end{tabular}


FERREIRA, L.F.L., CARVALHO, A.U. e FERREIRA, H.I. Aplicação do náilon monofilamento na reparação intra-articular da ruptura do ligamento cruzado cranial em cães. PUBVET, Londrina, V. 7, N. 18, Ed. 241, Art. 1592, Setembro, 2013.

Tabela 2 - Classificação do movimento de gaveta segundo Person (1987).

\begin{tabular}{|cc|}
\hline GRAU & CLASSIFICAÇÃO \\
\hline- & sem deslocamento cranial da tíbia, articulação estável. \\
\hline+ & deslocamento cranial da tíbia aproximadamente de $10 \mathrm{~mm}$. \\
\hline++ & deslocamento cranial da tíbia aproximadamente de $20 \mathrm{~mm}$. \\
\hline $\begin{array}{l}++ \\
\text { articulação. } \\
\text { totalmente instável }\end{array}$ \\
\end{tabular}


FERREIRA, L.F.L., CARVALHO, A.U. e FERREIRA, H.I. Aplicação do náilon monofilamento na reparação intra-articular da ruptura do ligamento cruzado cranial em cães. PUBVET, Londrina, V. 7, N. 18, Ed. 241, Art. 1592, Setembro, 2013.

Tabela 3 - Resultado do exame clínico, avaliação do movimento de gaveta, nos animais dos grupos $A, B$, e C, no pós-operatório imediato e nos intervalos de 15 e 30 dias de pós-operatório, segundo a classificação de Person (1987).

\begin{tabular}{|l|l|l|l|l|}
\hline Animais & $\begin{array}{l}\text { MG } \\
\text { pós ruptura }\end{array}$ & $\begin{array}{l}\text { MG } \\
\text { pós cirúrgico }\end{array}$ & $\begin{array}{l}\text { MG } \\
\text { pós cirúrgico }\end{array}$ & \begin{tabular}{l} 
pós cirúrgico \\
\hline
\end{tabular} \\
\hline A1 & +++ & - & 15 dias & 30 dias \\
\hline A2 & +++ & - & ++ & + \\
\hline A3 & +++ & - & ++ & ++ \\
\hline A4 & +++ & - & - & - \\
\hline A5 & +++ & - & - & - \\
\hline A6 & +++ & - & + & + \\
\hline B1 & +++ & - & - & - \\
\hline B2 & +++ & - & - & - \\
\hline B3 & +++ & - & ++ & + \\
\hline B4 & +++ & - & - & - \\
\hline B5 & +++ & - & ++ & + \\
\hline B6 & +++ & - & - & - \\
\hline C1 & +++ & - & - & - \\
\hline C2 & +++ & - & - & - \\
\hline C3 & +++ & - & - & - \\
\hline C4 & +++ & - & - & - \\
\hline C5 & +++ & - & - & - \\
\hline C6 & +++ & - & - & - \\
\hline
\end{tabular}


FERREIRA, L.F.L., CARVALHO, A.U. e FERREIRA, H.I. Aplicação do náilon monofilamento na reparação intra-articular da ruptura do ligamento cruzado cranial em cães. PUBVET, Londrina, V. 7, N. 18, Ed. 241, Art. 1592, Setembro, 2013.

\section{FIGURAS}

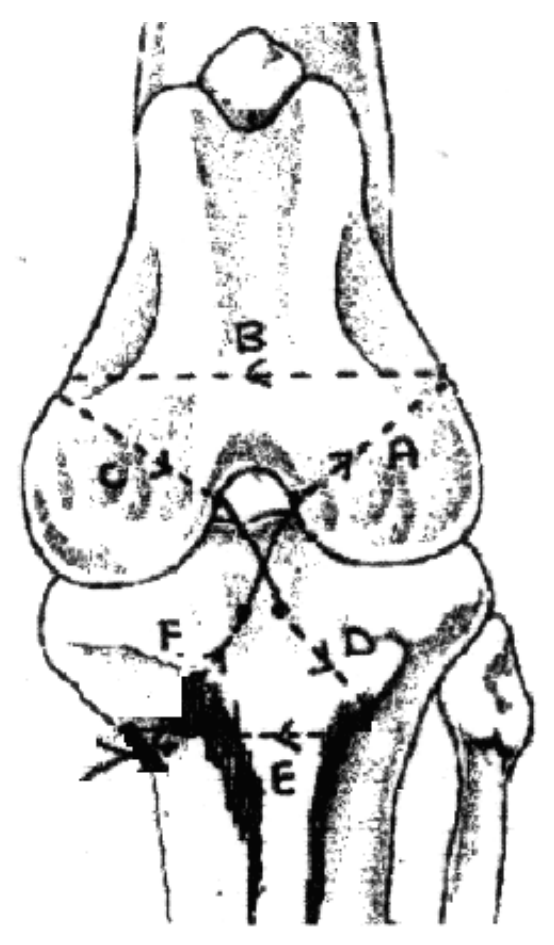

Medial

Lateral

Figura 1 - Apresentação esquemática das localizações e direções das perfurações, para colocação da prótese de náilon. 
FERREIRA, L.F.L., CARVALHO, A.U. e FERREIRA, H.I. Aplicação do náilon monofilamento na reparação intra-articular da ruptura do ligamento cruzado cranial em cães. PUBVET, Londrina, V. 7, N. 18, Ed. 241, Art. 1592, Setembro, 2013.

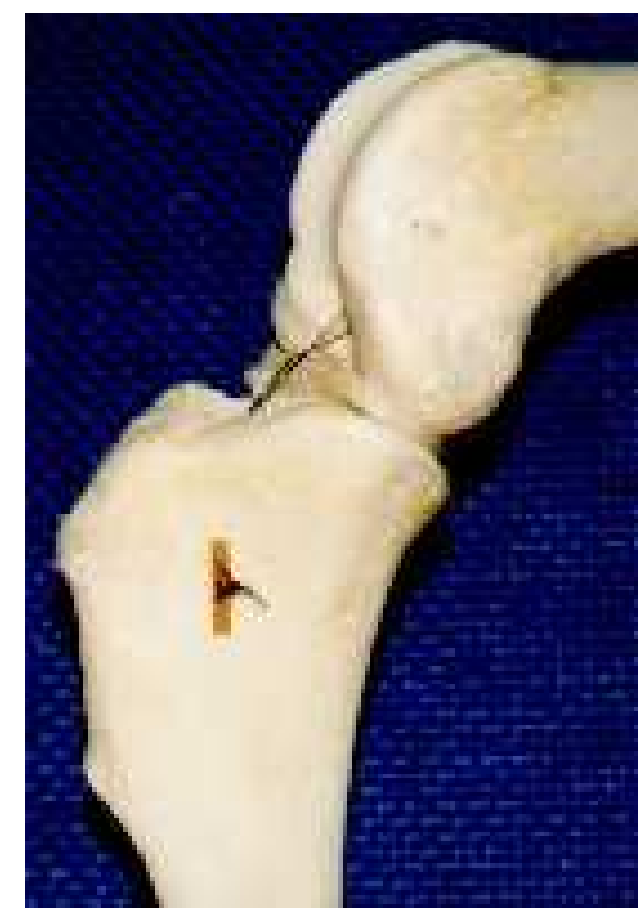

Figura 2 - Apresentação da prótese de náilon já colocada, com detalhe do capton na face medial proximal da tíbia, em peça óssea.

No de animais

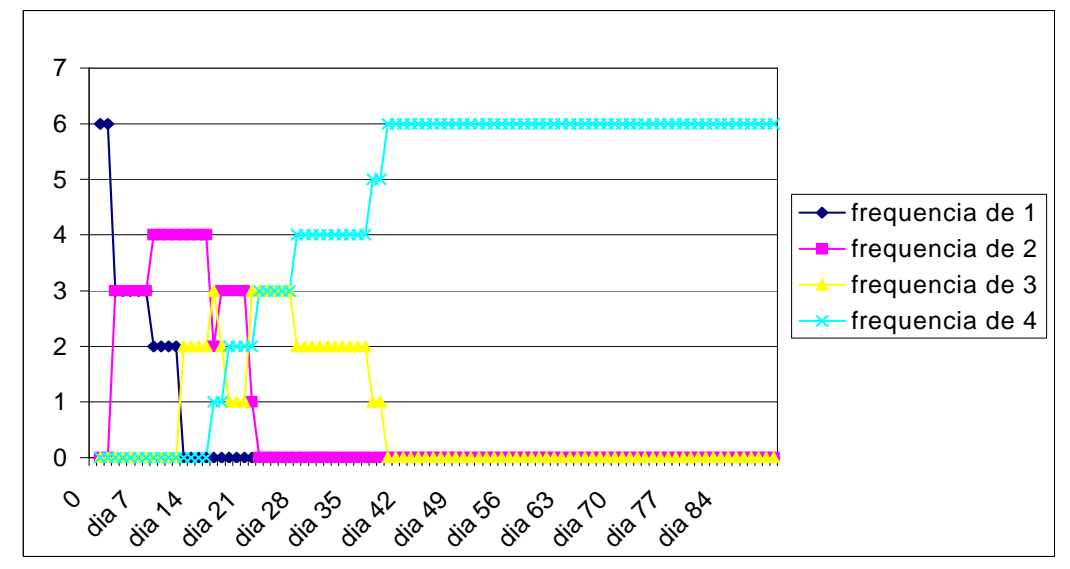

Dias observados, classificados segundo Braden \& Brinker (1973).

Figura 3 - Gráfico da análise da distribuição de freqüência do grau de claudicação nos animais do grupo A (90 dias) 
FERREIRA, L.F.L., CARVALHO, A.U. e FERREIRA, H.I. Aplicação do náilon monofilamento na reparação intra-articular da ruptura do ligamento cruzado cranial em cães. PUBVET, Londrina, V. 7, N. 18, Ed. 241, Art. 1592, Setembro, 2013.

No de animais

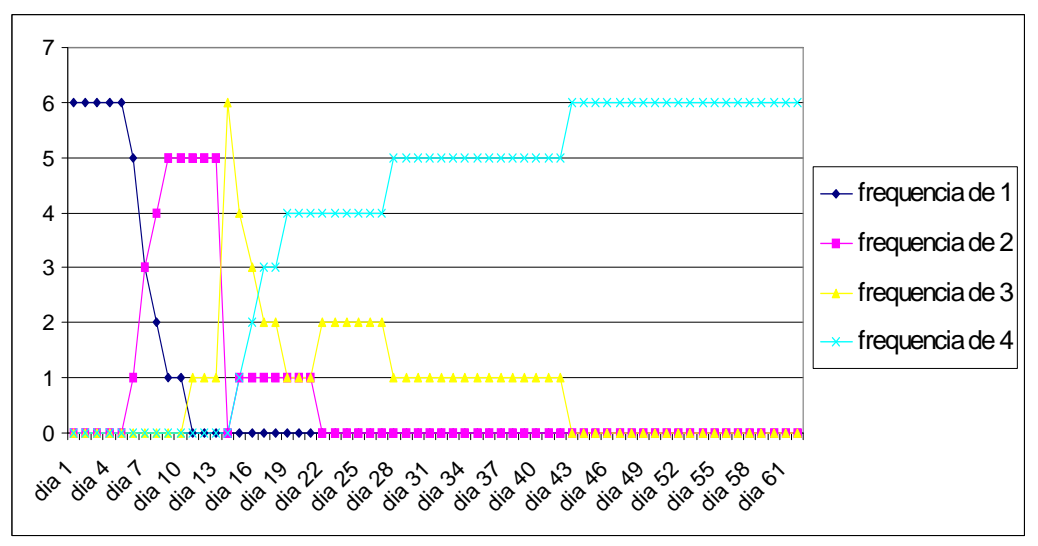

Dias observados, classificados segundo Braden \& Brinker (1973).

Figura 4 - Gráfico da análise da distribuição de freqüência do grau de claudicação dos animais do grupo B (60 dias)

No de animais

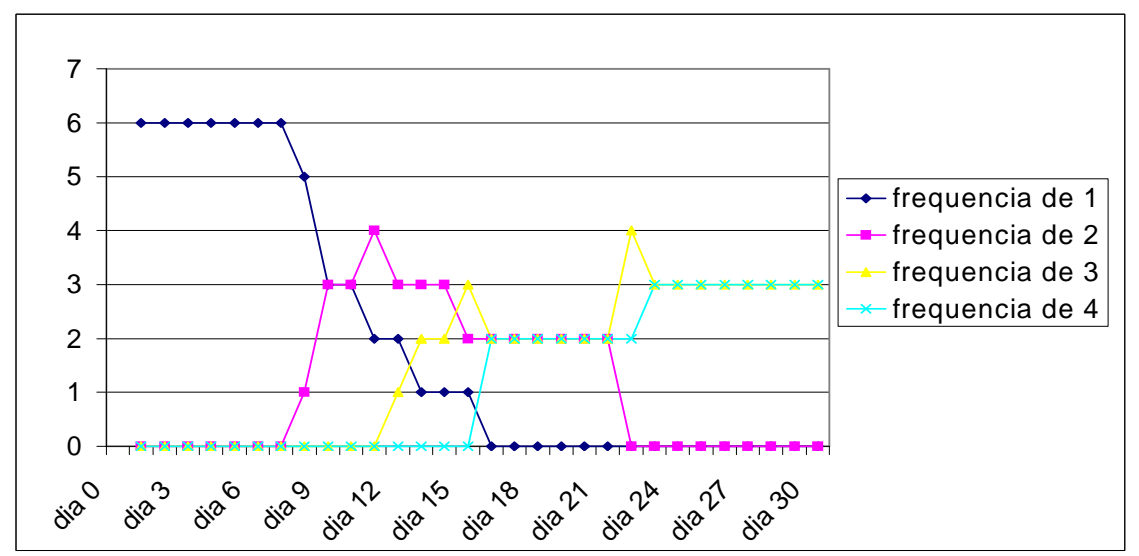

Dias observados, classificados segundo Braden \& Brinker (1973).

Figura 5 - Gráfico da análise da distribuição de freqüência do grau de claudicação dos animais grupo C (30 dias). 
FERREIRA, L.F.L., CARVALHO, A.U. e FERREIRA, H.I. Aplicação do náilon monofilamento na reparação intra-articular da ruptura do ligamento cruzado cranial em cães. PUBVET, Londrina, V. 7, N. 18, Ed. 241, Art. 1592, Setembro, 2013.

\section{REFERÊNCIAS BIBLIOGRÁFICAS}

ARNOCZKY, P.S. Pathomechanics of cruciate ligament and meniscal injuries. In: BOJRAB, M.J. (ed.) Disease mechanisms in small animal surgery. Philadephia: Lea \& Febiger, 1993, p.764777.

ARNOCZKY, P.S., MARSHALL, J. L. The cruciate ligaments of the canine stifle: an anatomical and functional analysis. America Journal of Veterinary Research, v.38, n.11, p.1807-1814, 1977.

ARNOCZKY, S.P., TARVIN, G.B., MARSHALL, J.L., SALTZMAN, B. The over-the-top procedure: a technique for the anterior cruciate ligament substitution in the dog. Journal of the American Animal Hospital Association, v.15, p.283-290, 1979.

BRADEN, T.D., BRINKER, W.O. Effect of certain internal fixation devices on functional limb usage in dogs. Journal of the American Medical Association, v.162, n.8, p. 642-646, 1973.

BRINKER, W. O., PIERMATTEI, D.L., FLO, G.L. Diagnosis and treatment of orthopedic conditions of the hindlimbs. In: BRINKER, W.O ., PIERMATTEI, D.L., FLO, G.L. (ed.) Handbook of small animal orthopedics and fracture treatment. 2. ed. Philadelphia: W.B. Saunders, 1990, p. 341470.

BUTLER, H.C. Teflon as a prosthetic ligament in repair of ruptured anterior cruciate ligaments. American Journal of Veterinary Research, v.25, n.104, p. 55-59, 1964.

GUPTA, B.N., BRINKER, W.O . Anterior cruciate ligament prosthesis in the dog. Journal of the American Veterinary Medical Association, v.154, n.9, p.1057-1061, 1969.

HULSE, D. A., SHIRES, P. K. The stifle joint. In: SLATTER, D.H. (ed.) Textbook of small animal surgery. Philadelphia:W.B. Saunders, 1985, p.2193-2235.

JOHNSON, F.L. Prosthetic anterior cruciate ligament. Journal of the American Veterinary Medical Association, v.137, n.11, p. 646-647, 1960.

JOHNSON, J. A., JOHNSON, A. L. Cranial cruciate ligament rupture: pathogenesis, diagnosis, and postoperative rehabilitation. The Veterinarian Clinics of North America Small Animal Practice, v.23, n.4, p.717-733, 1993.

KNECHT, C. D. Evolution of surgical techniques for cruciate ligament rupture in animals. Journal of the American Animal Hospital Association, v.12, n.6 p.717-726, 1976.

MOORE, K. W., READ, R. A. Rupture of the cranial cruciate ligament in dogs -Part I. Compedium on Continuing Education, v.18, n.3, p.223-234, 1996.

PERSON, M.W. Prosthetic replacement of the cranial cruciate ligament under arthroscopic guidance. A pilot project. Veterinary Surgery, v.16, n.1, p. 37-43, 1987.

SELMI, L.G., PADILHA, J.G., EIMANTAS, G.C., CHIERICHETTI, A .L., BRASIL, F.B. Prótese de poliéster trançado na reparação intra-articular da ruptura do ligamento cruzado cranial em cães. In: II CONGRESSO BRASILEIRO DO CBCAV, 1996, Ribeirão Preto. Anais...Ribeirão Preto: 1996, p.41. Resumo. 
SELMI, L.G., PADILHA, J.G., BUQUERA, L.E., HONSHO, D.K. Avaliação clínica da prótese sintética de Leeds-Keio como substituto ao ligamento cruzado cranial em cães. In: III CONGRESSO BRASILEIRO DO CBCAV, 1998, Belo Horizonte. Anais... Belo Horizonte: 1998, p.57. Resumo.

SHIRES, P.K., HULSE, D.A., LIU, W. The under-and-over fascial replacement for anterior cruciate ligament rupture in dogs: a retrospective study. Journal of the American Animal Hospital Association, v.20, p. 69-77, 1984

VASSEUR, P. B. Clinical results following nonoperative management for rupture of the cranial cruciate ligament in dogs. Veterinary Surgery, v.13, p.243-251, 1984.

VASSEUR, P. B., GRIFFEY, S., MASSAT, B. J. Evaluation of the Leeds-Keio synthetic replacement for the cranial cruciate ligament in dogs: an experimental study. Veterinary Comparative Orthopaedics and Traumatology, v.9, n.2, p.66-74, 1996.

VASSEUR, P.B., RODRIGO, J.J., STEVENSSON, S., CLARK, G. Replacement of the cranial cruciate ligament with a bone-ligament-bone cranial cruciate ligament allograft. Veterinary Surgery, v.15, n.1, p.137, 1986. 